\begin{abstract}
Iranica
Abstracta Iranica Revue bibliographique pour le domaine irano-aryen

Volume 34-35-36 | 2017

Comptes rendus des publications de 2011-2013
\end{abstract}

\title{
Samuel R. Wolff. Basket-Handled Amphoras in the Hecht Museum
}

\section{Astrid Nunn}

\section{(2) OpenEdition}

1 Journals

\section{Édition électronique}

URL : http://journals.openedition.org/abstractairanica/41554

DOI : 10.4000/abstractairanica.41554

ISSN : 1961-960X

Éditeur :

CNRS (UMR 7528 Mondes iraniens et indiens), Éditions de l'IFRI

Référence électronique

Astrid Nunn, "Samuel R. Wolff. Basket-Handled Amphoras in the Hecht Museum», Abstracta Iranica [En ligne], Volume 34-35-36 | 2017, document 27, mis en ligne le 15 juillet 2016, consulté le 28 septembre 2020. URL : http://journals.openedition.org/abstractairanica/41554 ; DOI : https://doi.org/10.4000/ abstractairanica. 41554

Ce document a été généré automatiquement le 28 septembre 2020.

Tous droits réservés 


\title{
Samuel R. Wolff. Basket-Handled Amphoras in the Hecht Museum
}

\author{
Astrid Nunn
}

\section{RÉFÉRENCE}

Samuel R. Wolff. «Basket-Handled Amphoras in the Hecht Museum ». Michmanim, 23, 2011, p. 15-19.

Michmanin est le périodique annuel du Hecht Museum de Haifa. Les articles ont donc un lien soit avec les collections soit avec des fouilles menées par ce musée. L'A. (du Service des Antiquités d'Israël) s'attache ici aux amphores à anse en panier découvertes lors de fouilles. Plusieurs exemples en sont conservés au Hecht Museum. L'A. traite leur origine - Chypre plutôt que Rhodes -, leur datation - de la fin du VIII ${ }^{e}$ au II ${ }^{e}$ s. av. J.-C. et leur distribution géographique confinée à la Méditerranée orientale. Les volumes peuvent être divisés en deux groupes. l'A. se demande si cette différence n'est pas due à la denrée transportée, en l'occurrence de l'huile ou du vin. Ce type d'amphore existe également en petit format/dimension. D'après l'A., ces miniatures servaient également au transport d'huile d'olive tout en représentant à la fois des objets votifs.

\section{AUTEURS}

\section{ASTRID NUNN}

Université de Munich 